\title{
Museus Corporativos Estratégicos: Uma Análise do Espaço de Memória da Cervejaria Bohemia
}

\section{Strategic Corporate Museums: An Analysis of the Bohemia Brewery}

\author{
Alessandra de Sá Mello da Costa \\ Doutora em Administração pela EBAPE/FGV. \\ Professora Adjunta do Departamento de Administração da Pontifícia Universidade Católica \\ do Rio de Janeiro (IAG/PUC-Rio) \\ Rua Marquês de São Vicente, 225 - Prédio IAG - Gávea - Rio de Janeiro, RJ \\ CEP: 22451-900 \\ E-mail: alessandra.costa@iag.puc-rio.br
}

\section{Rafael Cuba Mancebo}

Doutorando em Administração. Programa de Pós-Graduação em Administração da Pontifícia Universidade Católica do Rio de Janeiro (IAG/PUC-Rio)

Rua Marquês de São Vicente, 225 - Prédio IAG - Gávea - Rio de Janeiro, RJ

CEP: 22451-900

E-mail: cuba.mancebo@gmail.com

\section{Luís Alexandre Grubits De Paula Pessoa}

Doutor em Letras pela Universidade Presbiteriana Mackenzie.

Professor Adjunto do Departamento de Administração da Pontifícia Universidade Católica do Rio de Janeiro (IAG/PUC-Rio)

Rua Marquês de São Vicente, 225 - Prédio IAG - Gávea - Rio de Janeiro, RJ

CEP: 22451-900

E-mail: lpessoa@iag.puc-rio.br 


\title{
Resumo
}

O interesse das empresas em constituir seus espaços históricos não é recente. Com o passar do tempo, entretanto, os museus corporativos são ressignificados e ao lado dos museus tradicionais (uma estrutura estática com a exposição de objetos antigos que contam a história da empresa e serve como um depósito histórico) surge o museu estratégico, onde a memória passa a ser um ativo estratégico da organização. Neste contexto, esta pesquisa buscou identificar, descrever e problematizar o tour pela fábrica da Cervejaria Bohemia como um espaço estratégico de memória corporativa. Para alcançar este objetivo - a partir dos dados coletados em visitas feitas à Cervejaria com registros em fotos, vídeos, anotações de campo e coleta de documentos institucionais - as salas que compõem o percurso de visitação foram analisadas à luz das quatro funções primárias dos museus corporativos. Como resultado, duas funções não foram identificadas, quais sejam preservar a história da empresa e desenvolver um senso de orgulho e identificação do empregado. As demais foram identificadas: em todo o percurso o visitante é informado sobre a empresa e sua linha de produtos e pode-se considerar que o museu é efetivamente utilizado como forma de impactar positivamente a opinião pública. Assim, pode-se afirmar que este espaço, no que diz respeito à construção de uma identidade organizacional, ainda não explorou todo o seu potencial estratégico, parecendo tender para uma configuração que privilegia apenas uma função utilitária bem específica para o uso da memória e de fatos históricos: legitimar a sua marca empresarial.

Palavras-chave: História de empresas; Museus corporativos; Memória Organizacional; Cervejaria Bohemia.

\begin{abstract}
The interest of companies in establishing their historical spaces is not new. Over time, however, corporate museums have been resignified and, alongside traditional museums (static structures with the exhibition of old objects that tell the story of the company and serve as historical deposits), the strategic museum arises and the memory becomes a strategic asset of the organization. In this context, this research has sought to identify, describe and discuss the tour through the Cervejaria Bohemia factory as a strategic area of corporate memory. To achieve this goal - from the data collected in visits to the brewery that has been recorded in photos and videos, including field notes and a collection of institutional documents - the rooms that make up the visitation route have been analyzed in the light of the four primary functions of corporate museums. As a result, two functions have not been identified, namely, preserving the history of the company and developing a sense of pride and employee identification. The others have all been identified: all through their way visitors are informed about the company and its product line; thus it can be considered that the museum is actually used as a way to positively impact the public opinion. Nevertheless, when it comes to the construction of an organizational identity, it can be said that this space has not yet explored all its strategic potential, apparently tending to a setting that only favors a very specific utilitarian function for the use of memory and historical facts: to legitimize their business brand.
\end{abstract}

Keywords: Corporative History; Corporate Museums; Organizational Memory; Bohemia Brewery. 


\section{Introdução}

Em maio de 2015, na primeira página do sítio eletrônico oficial da Cervejaria Bohemia, ao invés dos seus novos lançamentos, o que adquiria destaque era o seu passado, mais especificamente a sua história e as suas memórias materializadas na visita guiada em seu museu corporativo. A primeira informação refere-se ao prêmio recebido do Guia 4 Rodas: "Eleita novidade do ano no Prêmio O Melhor do Guia Brasil 2013, do Guia Quatro Rodas, a Cervejaria Bohemia já recebeu mais de 80 mil pessoas desde sua reabertura ao público em 2012" (Bohemia, 2015a). A segunda diz respeito ao certificado de excelência concedido pelo TripAdvisor, dentro da categoria museus/museus especializados: "Em 2014, a Cervejaria Bohemia recebeu o Certificado de Excelência do TripAdvisor. É o nosso Tour fazendo sucesso com a história da cerveja!" (Bohemia, 2015b).

Este movimento de atribuição de destaque e ênfase à sua história, promovido pela Cervejaria Bohemia, insere-se em um contexto mais amplo e reflete a crescente importância atribuída por parte das empresas, da sociedade e do mercado aos museus em geral, e aos museus corporativos, em particular. Processo de museificação da sociedade? Segundo Lipovetsky (2004, p.81), "dizem de brincadeira que abre um museu por dia na Europa, e já se perdeu a conta das comemorações de aniversários dos grandes e nem tão grandes acontecimentos históricos. Em nossa época, o que não se presta mais a ser objeto de museu, de restauração, de celebração?". No caso dos museus corporativos, os exemplos são vários: Heineken Experience, em Amsterdam; World Coca Cola, em Atlanta; BMW Museum, em Munique; Mercedes-Benz Museum, em Stuttgart; The Henry Ford Museum, em Dearborn; Harley-Davidson Museum, em Milwaukee, entre outros. No caso dos museus corporativos brasileiros, podemos destacar o Museu TAM, em São Carlos; o Museu do Chocolate Garoto, em Vitória; o Museu Hering, em Blumenau; o Tour Nestlé Chocolover, em Caçapava. Todos, apesar das distâncias geográficas, possuem objetivos semelhantes: serem um espaço de memória (coletiva ou episódica), onde as experiências são construídas e compartilhadas, legitimando e divulgando a história e as ações da organização.

Ao mesmo tempo em que cresce o interesse das empresas, este fenômeno também passa a chamar a atenção de pesquisadores que buscam identificar e analisar como o resgate e a gestão de uma determinada trajetória histórica (com seus desdobramentos em narrativas memorialísticas) podem ser usados de forma estratégica pelas empresas tanto em uma perspectiva mais instrumental (ver: Nassar, 2007; Ribeiro \& Barbosa, 2007; Figueiredo, 2009) quanto em uma abordagem mais crítica (ver: Nissley \& Casey, 2002; Booth \& Rowlinson, 2006; Foster et al, 2011; Costa \& Saraiva, 2011).

Uma das formas possíveis de pensar sobre esse movimento de constituição de espaços empresariais de história e de memória é assumir que o passado começa a ser valorizado pelas empresas como uma forma de registrar e perpetuar trajetórias pretendidas em "lugares de memória" que, com características simbólicas, materiais ou funcionais preservam o passado (Nora, 1992). Cabe ressaltar que, trabalhar com a ideia da existência de lugares de memória significa atribuir a estes lugares um significado de espaço de construção e reconstrução de uma memória socialmente compartilhada e, por isso, coletiva. E no caso das empresas, um lugar de memória por excelência são, exatamente, os Museus Corporativos (Nissley \& Casey, 2002). Ou seja, constituído a partir de uma dinâmica relação com os atores sociais, apresentase como produtor e disseminador de sentidos (Andreoni, 2011). Neste contexto, a presente pesquisa teve por objetivo identificar, descrever e problematizar o tour pela fábrica da Cervejaria Bohemia como um espaço estratégico de memória corporativa. 


\section{Museus Corporativos Estratégicos}

O interesse das empresas em constituir espaços de história e memória não é recente. Pelo contrário, iniciou-se - de acordo com Danilov (1992) - no século XIX como resultado de tentativas de proteger e salvaguardar registros documentais; objetos considerados representativos e dignos de memória; e outros artefatos relacionados com o processo de trabalho e com a indústria. Configuradas na forma de arquivos fotográficos, documentos, desenhos, protótipos, máquinas, produtos e na (re)construção das próprias narrativas, as memórias das empresas e dos seus fundadores iam adquirindo materialidade e legitimidade como história e memórias oficiais (Danilov, 1992).

Os museus corporativos são construídos dentro das próprias empresas ou em suas proximidades. Em relação às políticas de admissão nestes espaços de memória, os modelos variam: algumas empresas cobram taxas de entrada; em outras a entrada é gratuita; e em alguns casos o acesso pode ser restrito apenas aos funcionários e convidados (Stigliani e Ravasi, 2007). Em sua versão mais contemporânea, os museus corporativos podem também adquirir diferentes formatos, tais como instalações em salas de exposições, centros de visitantes, centros de informação e visitas guiadas às fábricas (Danilov, 1992; Nissley e Casey, 2002). De qualquer forma, Danilov (1992) argumenta que, independente do formato que a empresa escolha implantar, quatro funções primárias podem ser identificadas como inerentes aos museus corporativos: (1) preservar a história da companhia; (2) desenvolver um senso de orgulho e identificação do empregado com a empresa; (3) informar visitantes e clientes sobre a empresa, sua linha de produtos ou serviços; (4) influenciar a opinião pública sobre a companhia.

Com o passar do tempo, entretanto, o objetivo final destas funções primárias (ou o seu fundamento essencial) sofre alterações. Isto é, nas palavras de Andreoni (2011, p.169), os museus são ressignificados e as tradicionais "premissas de conservação cedem espaço para a comunicação". Na perspectiva das empresas, se nos primeiros museus corporativos o foco maior incidia sobre questões históricas como “(...) a história da empresa, (...) as contribuições do fundador e outros indivíduos-chave e a exibição de documentos, fotografias e produtos do passado" (Nissley e Casey, 2002, p.36), nos dias de hoje a ênfase recai diretamente em questões de relações públicas, marketing e/ou no que Rhees (1993) denomina como publicidade educacional. De acordo com este autor - que estudou o caso da empresa Du Pont "não se pode interpretar corretamente os significados culturais e as funções sociais dos museus da ciência e da indústria sem compreender o contexto da publicidade corporativa e relações públicas dentro das quais as exposições industriais são construídas" (Rhees, 1993, p.67).

Como desdobramento desta ressignificação e da responsabilidade de gestão dos espaços de memória pelas áreas de Comunicação, alguns pesquisadores passam a buscar compreender os museus corporativos como espaços de experiências de marca. No atual contexto de mercado, a realização de eventos e experiências, também denominada "marketing experiencial ou de experiências", tem significativo papel na comunicação das organizações, figurando ao lado de ferramentas tradicionais como propaganda e promoção de vendas. Kotler e Keller (2012, p. 514) definem eventos e experiências como

atividades e programas patrocinados por uma empresa e destinados a criar em uma base diária, ou em ocasiões especiais, interações com os consumidores, que estejam associadas à marca, incluindo esportes, artes, entretenimento e eventos associados a uma causa social, bem como atividades menos formais.

Os mesmos autores, ao se referirem à criação de experiências, sugerem que 
as empresas podem até mesmo criar uma imagem forte ao convidar consumidores em potencial e clientes a visitar sua sede e fábricas. Empresas como Ben \& Jerry, Boeing, Crayola e Hershey patrocinam excelentes visitas a suas instalações, atraindo milhões de visitantes por ano. Outras como Hallmark, Kohler e Beiersdorf (fabricantes do creme Nivea) construíram museus corporativos em suas sedes ou nas proximidades para mostrar sua história e o que envolve a fabricação e o marketing de seus produtos (Kotler e Keller, 2012, p. 564, grifo nosso).

Dessa maneira, os museus corporativos são atualmente considerados um importante canal estratégico para as organizações se comunicarem com seus stakeholders, estreitando laços de identificação e contribuindo para o desenvolvimento da identidade organizacional e da imagem da organização.

O tema da identidade organizacional é um bom exemplo da utilização dos espaços de memória empresariais como canal estratégico (ver, por exemplo, os estudos de Anteby \& Molnar, 2012; Schultz \& Hernes, 2013; Castellani \& Rossato, 2014). Uma história oficial coerente, construída por meio de uma narrativa bem estruturada, sistematizada e exposta para os diferentes públicos de interesse nos museus corporativos é considerada por vários autores como estratégica (ver: Rowlinson et. al, 2010; Ravasi, 2014). Conforme Ravasi (2014, p.44) argumenta,

as declarações de identidade organizacional são mais verossímeis, internamente e externamente, à medida que versam sobre a história da organização e são apresentadas como o legado de um passado compartilhado (...) [Ou seja] as identidades organizacionais são mais facilmente "descobertas" do que "inventadas" (...) [e] profissionais de comunicação podem ajudar a orquestrar reflexões internas, envolvendo um quadro maior de atores, para identificar características de centralidade, sustentação e diferenciação da organização, com base na reconstrução de sua história.

Ainda nessa mesma linha de raciocínio, Nissley e Casey (2002) argumentam que tanto a identidade quanto a imagem organizacional são construídas e reconstruídas por meio dos museus corporativos, que servem como uma especie de alma da empresa:

Por exemplo, a Coca-Cola, Ford, Motorola e Hershey criaram museus corporativos que não só apoiam objetivos históricos, mas também funcionam estrategicamente como instalações de treinamento de funcionários que servem de relações públicas da empresa e estratégias de relações de empregado (...). Assim, as organizações podem criar a sua identidade usando o museu corporativo como um local para orientar novos funcionários e formação de pessoal. O museu representa quem são por meio da exibição que eles foram. Marketing e criação de uma imagem também são funções-chave para muitos museus corporativos (Nissley \& Casey, 2002, p.40).

Como desdobramento deste novo direcionamento (ou ressignificação), ao lado da ideia de museu tradicional (considerado como uma estrutura estática com a exposição de objetos e produtos antigos que contam a história da empresa e serve como um depósito histórico) surge o museu estratégico, onde a memória organizacional passa a ser compreendida como um ativo estratégico da organização. De forma a melhor compreender as diferenças e aproximações entre estas duas perspectivas diferentes de museus, Nissley e Casey (2002) apresentam uma revisão de literatura das tipologias da memória organizacional, conforme a figura 1 abaixo: 


\begin{tabular}{|l|cc|}
\hline Memória organizacional & Tradicional & Estratégico \\
\hline $\begin{array}{l}\text { Repositório (e.g Huber, 1991; Huber, Davenport and King, 1998; } \\
\text { Walsh and Ungson, 1991) }\end{array}$ & $\mathrm{X}$ & $\mathrm{X}$ \\
\hline Memória Coletiva (e.g. Casey, 1997; Halbwachs, 1980) & $\mathrm{X}$ \\
\hline $\begin{array}{l}\text { Memória Semântica (e.g Casey, 1997; Stein and Zwass, 1995, } \\
\text { p.89) }\end{array}$ & & $\mathrm{X}$ \\
\hline Memória Episódica (Casey, 1997; Stein and Zwass, 1995, p.89) & $\mathrm{X}$ \\
\hline Memória Cultural (e.g Sturken, 1997) & $\mathrm{X}$ \\
\hline
\end{tabular}

Figura 1 - Tipos de memória organizacional e museus corporativos Fonte: Adaptado de Nissley e Cassey, 2002.

Os museus tradicionais vinculam-se aos tipos de memória como repositório; memória semântica; e memória cultural. No que diz respeito aos museus denominados como estratégicos, os tipos de memórias vinculados são a memória coletiva, a memória episódica e a memória cultural. Deve-se ressaltar que tanto o museu corporativo tradicional quanto o estratégico são resultados das escolhas narrativas da organização, que guiam os visitantes em uma jornada histórica que ensina sobre culturas antigas e que, em alguns casos, até relaciona o indivíduo com uma coletividade nacional (Barndt, 2007).

A memória organizacional como repositório prioriza a identificação de expressões da memória da empresa em seus respectivos sistemas de informações, em sua arquitetura, em suas orientações estratégicas, em seus procedimentos de operação padronizados (Walsh \& Ungson, 1991). Entende-se que a memória organizacional reduz custos de transação (limitando o percentual de busca e análise em situações de tomada de decisão similares ou repetidas); organizam, coordenam, integram e legitimam atividades organizacionais; e criam uma base para adaptação para processos de inovação e aprendizagem organizacional (Feldman \& Feldman, 2006).

No que diz respeito à memória organizacional como memória coletiva, esta se vincula à ideia de memória socialmente compartilhada, apresentada por Halbwachs (1941) como uma reconstrução do passado a partir das crenças e necessidade do presente. Preocupado com os níveis sociais da memória, este autor argumenta que a memória dos indivíduos depende do seu relacionamento social (relações familiares, políticas, religiosas, profissionais, entre outras) uma vez que "(...) é na sociedade que as pessoas normalmente adquirem suas memórias (Halbwachs, 1992, p.38). É também na sociedade que elas recordam, reorganizam e localizam as suas memórias". Neste sentido, a memória é sempre uma memória dos indivíduos (apesar do processo de relembrar ser social) e (b) a memória coletiva é o processo por meio do qual as ideias individuais são influenciadas pelas ideias dos grupos ao quais estes indivíduos pertencem (Halbwachs, 1992). De forma mais específica, a memória coletiva forma-se por meio das narrativas, contidas nos símbolos e rituais da organização, datas comemorativas ou nome de edifícios e salas (Rowlinson et al, 2010). Ou seja, a memória como um ato coletivo organizacional ocorre por meio de um processo social de construção e compartilhamento (Nissley \& Casey, 2002), materializando-se - particularmente - em projetos de museus estratégicos.

A memória organizacional como memória cultural, identificada tanto nos museus tradicionais quanto nos estratégicos, é a memória construída por meio de negociações sociais (Nissley \& Casey, 2002), ou seja, encontrada nos objetos e documentos expostos, mas Museus Corporativos Estratégicos: Uma Análise do Espaço de Memória da Cervejaria Bohemia 
também na narrativa da visita ao museu, na história socialmente construída e na história formalmente contada.

A memória organizacional como memória semântica, por sua vez, forma-se a partir de experiências compartilhadas de eventos que, no entanto não foram vividos pessoalmente. Ao contrário, a memória episódica constitui-se a partir das memórias dos membros da organização. Acontecimentos que foram vividos individualmente (Rowlinson et al, 2010) são estrategicamente selecionadas e compartilhadas, de modo que componha uma história da organização, sua cultura e identidade. Um exemplo são os depoimentos e história de vida dos fundadores e o destaque a características esperadas na organização (i.g enfrentar desafios, priorizar a empresa, dedicação integral, alcance de resultados, entre outros).

No caso dos museus corporativos estratégicos, a memória episódica se compõe com a memória coletiva. Ou seja, o museu conta a sua história e enquadra as suas memórias tanto a partir da perspectiva das pessoas que viveram e experimentaram os eventos narrados quanto a partir da perspectiva daqueles que não participaram efetivamente do evento, mas compartilham de um processo de construção social por meio da experiência, como por exemplo, das visitas guiadas. Assim, os museus corporativos assumem o papel de depositários da história e da memória das organizações, conectando, como já foi dito, história e memória a partir dos artefatos que exibem, das narrativas que orientam a visita (Nissley \& Casey, 2002).

\section{Procedimentos metodológicos}

De forma a embasar e conduzir os protocolos metodológicos requeridos, os dados foram coletados em três momentos diferentes, representados por três visitas feitas à Cervejaria Bohemia, em julho e setembro de 2014 e em agosto de 2015.

As duas primeiras visitas tiveram um caráter exploratório, tendo por objetivo registrar em fotos, vídeos e anotações de campo (a) o percurso e a narrativa da visita; (b) os objetos apresentados; (c) as informações expostas; e (d) a experiência de consumo na qual a visita se transforma. Ao mesmo tempo, também foram coletados e analisados documentos institucionais acerca da história da empresa, da história de constituição do museu corporativo, além de discursos publicitários e ações promocionais. A terceira visita teve como objetivo aprofundar a pesquisa em pontos considerados mais relevantes para o alcance do objetivo final quando os pesquisadores buscaram: (1) aprofundar a descrição do percurso do Tour; (2) aprofundar, de forma a melhor entender, a relação entre as diferentes narrativas presentes no Tour e a construção da identidade organizacional (a partir do direcionamento dado pelas categorias (a) Sucesso, ou as narrativas sobre como a organização está bem estabelecida; (b) Obstáculos, ou as narrativas sobre quais os obstáculos que a organização teve que superar; (c) Situação atual, ou as narrativas sobre como a organização apresenta-se hoje; e (d) Futuro, ou as narrativas sobre o que o futuro reserva para a organização); e (3) aprofundar, de forma a melhor entender, como a organização usa as memórias coletiva, episódica e cultural (quais e em que momento) neste processo.

\section{A análise do Tour Histórico pela Cervejaria Bohemia}

De acordo com as informações divulgadas pelo museu, a Bohemia é a primeira cervejaria do Brasil e foi fundada em 1853 durante o período imperial brasileiro. Criada pelo alemão Henrique Kremer a empresa possuía o nome de Imperial Fábrica de Cerveja Nacional (1848) e desfrutava do status de fornecedora da Casa Imperial. Mais tarde, passou a se chamar Companhia Cervejaria Bohemia. De forma complementar, pode-se encontrar no site da marca a informação de que a cerveja hoje é líder do segmento Premium, faz parte do grupo Ambev e tem vários tipos de cerveja diferentes, Bohemia Pilsen, Bohemia Confraria, 
Bohemia Escura e Bohemia Weiss. Ainda conforme o site, a empresa afirma que seus produtos são feitos artesanalmente, mantendo a mesma fórmula que atinge um padrão tradicional de qualidade até os dias atuais, sendo produzida por seis fábricas da Ambev espalhadas pelo Brasil (2014a).

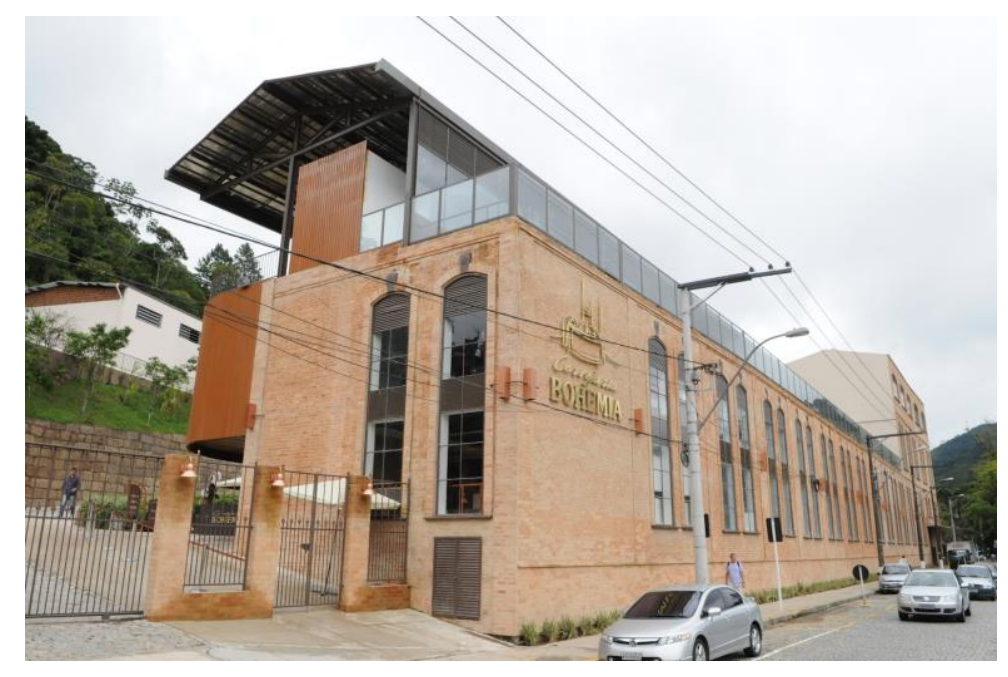

Figura 2 - Visão externa da Fábrica da Bohemia em Petrópolis. Fonte: Próprios autores.

A antiga fábrica localizada na cidade de Petrópolis, região serrana do estado do Rio de Janeiro foi reaberta em 2012 com uma nova estrutura e um novo propósito: ser um espaço de memória da cerveja Bohemia:

(...) Nesta sexta-feira, 18 de maio, a construção de tijolinhos reabre as portas: mais que produzir louras, ruivas e morenas, o prédio se transformou em um moderno, lúdico e imperdível museu temático, onde aprendemos tudo sobre a cerveja: a origem, a história, o processo de elaboração e os vários estilos" (Jornal O GLOBO, 2014a).

Aberto há pouco mais de um ano, o Museu da Cerveja na Cervejaria Bohemia já atraiu mais de 50 mil visitantes. No centro de experiência cervejeira, o visitante conhece como surgiu a primeira cerveja do Brasil, mas também a história da cerveja desde o início da humanidade" (Jornal O GLOBO, 2014b).

O projeto do espaço de memória foi criado pela CRIACITTÁ, uma empresa de comunicação com foco em cenografia, que desenvolve ambientes físicos para marcas e inspirado nos espaços corporativos da Heineken Experience e da Guinness Storehouse (a Fábrica da Bohemia e o seu tour em vários momentos são chamados de Bohemia Experience) (Jornal O GLOBO, 2014). Como destacado já pela literatura (Stigliani e Ravasi, 2007), o espaço seguiu a tendência de outros projetos e foi construído dentro da própria fábrica em funcionamento.

Em relação ao processo de visitação, o tour na fabrica está dividido em vinte ambientes, todos com atividades interativas, organizados para fins desta pesquisa, em três etapas: (1) A história da cerveja Bohemia como a história da cerveja: apresenta o contexto histórico da cerveja (sua criação, suas curiosidades e sua história); os tipos de cerveja e suas regiões de origem; (2) O processo produtivo da cerveja Bohemia: apresenta os tipos de malte, lúpulo e levedura, as máquinas usadas na produção; a sala do mestre cervejeiro, onde o laboratório da família é reproduzido em uma espécie de laboratório alquimista com objetos, fotos e rótulos usados pelos mestres cervejeiros ao longo do tempo, e uma degustação inicial Museus Corporativos Estratégicos: Uma Análise do Espaço de Memória da Cervejaria Bohemia 
rápida; e (3) A experiência de consumo da marca: promove uma degustação mais técnica de cervejas especiais e um espaço interativo com jogos lúdicos e brincadeiras.

\subsection{A História da Bohemia como a História da Cerveja}

Cabe-se destacar que, no que diz respeito à tipologia de Nissley e Casey (2002), as três memórias que configuram um museu organizacional como estratégico (memória coletiva, memória episódica e memória cultural) estão presentes no espaço em questão, e podem ser percebidas, por exemplo, no próprio roteiro do tour pela fábrica.

A primeira etapa pode ser vinculada a um processo de resgate de uma memória cultural, com ênfase em artefatos socialmente construídos, que no caso são relacionados à história e à fabricação da cerveja em uma perspectiva mais ampla. Assim, assumindo que a cerveja foi criada em 6.000 a.C, a primeira etapa começa neste período histórico e encaminha o visitante até as tecnologias mais atuais de fabricação.

Em um corredor que simula um rio de cerveja no chão, os painéis nas paredes conduzem a viagem no tempo até o local da fonte do "rio", a Bohemia. Durante o percurso, a história da empresa é relacionada com acontecimentos relevantes ocorridos no mundo e na história do Brasil. Dessa forma, a narrativa legitima a existência da empresa ao vinculá-la à própria trajetória histórica da cerveja e da cerveja no país. Para isso, painéis, telas sensíveis ao toque e objetos expostos contam sobre a evolução dos meios de comunicação, a criação do refrigerador, o surgimentos de técnicas de pasteurização e da linha de produção. Como ilustração, quando o contexto histórico era o do Brasil no início do século XIX, algumas telas mostram como a chegada da família Real portuguesa em 1808 fortaleceu a cerveja na colônia, endossando quarenta anos depois (em 1848) a criação da primeira cerveja do país, conforme ilustra a Figura 3 abaixo:
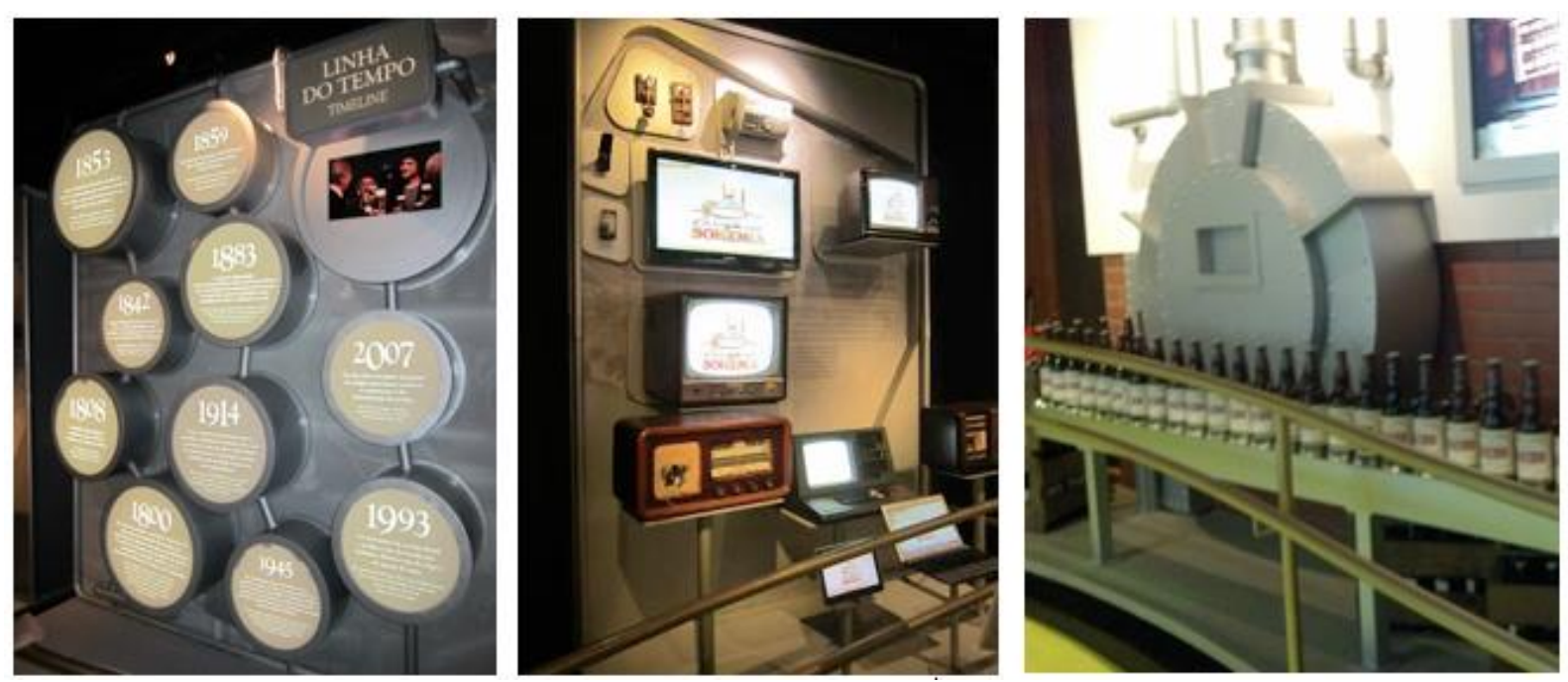

Figura 3 - Linha do tempo com acontecimentos relevantes para a produção e consumo de cerveja no mundo (e.g a invenção da geladeira em 1853), os avanços dos meios de comunicação e a produção em massa.

Fonte: Próprios autores

A história da cerveja e seus diferentes tipos pelo mundo se encerram na "fonte do rio de cerveja": a Bohemia. Neste momento, o visitante chega a uma segunda etapa onde poderá acompanhar, a partir de jogos interativos e vídeos, o processo de fabricação da cerveja Bohemia.

\subsection{O processo produtivo da Bohemia}

Costa, A. S. M.; Mancebo, R. C.; Pessoa, L. A. G. P. 
A segunda etapa da visita vincula-se mais especificamente à memória episódica e se inicia com a remontagem histórica da sala do mestre cervejeiro da Bohemia, onde objetos da época são expostos e a história da família é contada. Todas as informações apresentadas reforçam aspectos regionais e artesanais da cerveja e estão expostas embalagens, rótulos, artefatos da época, pinturas e fotos.

Como apresentado por Barndt (2007) em seu trabalho acerca do Museu Henry Ford, a arquitetura, a estética e as experiências sensoriais são poderosas ferramentas para a imersão dos visitantes na história da empresa. A passagem física da primeira etapa para a segunda etapa se dá por um saguão onde alguns painéis contam curiosidades históricas sobre a cidade, sua arquitetura e personagens ilustres, assim como, apresentam os rótulos das garrafas da cerveja e alguns anúncios de jornais da época, conforme Figura 4 abaixo:
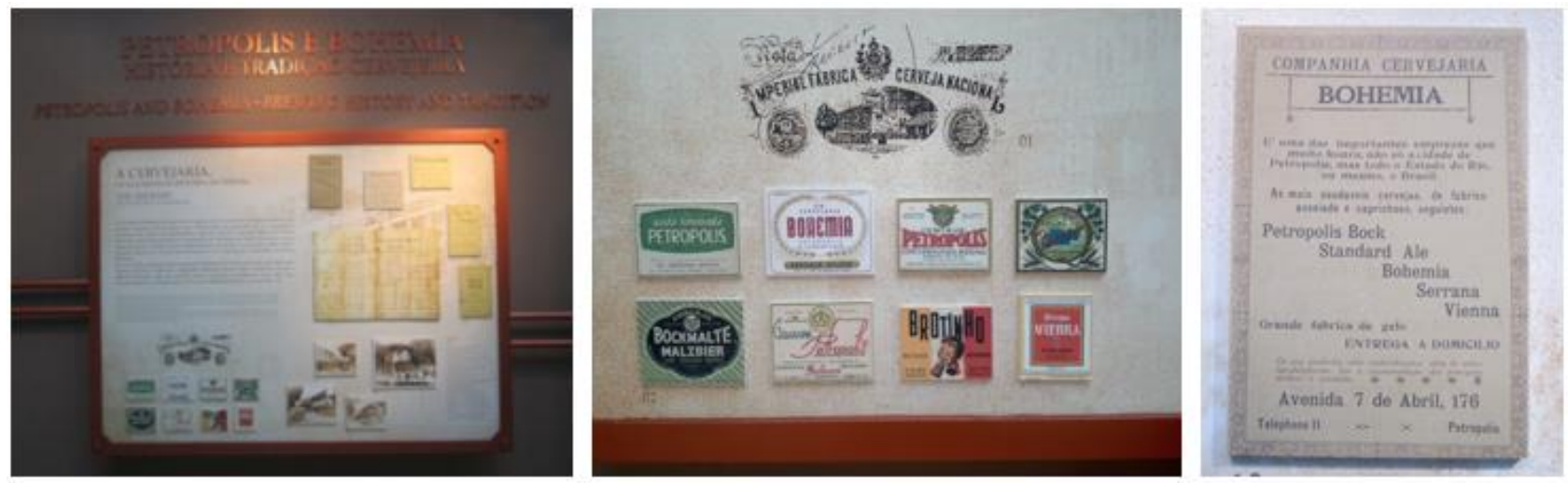

Figura 4 - Painel "Petrópolis e Bohemia: história e tradição cervejeira" com informações da empresa e da cidade de Petrópolis.

Fonte: Próprios autores.

Estes painéis reforçam os valores de tradição e vínculo entre a Bohemia e a história da cidade de Petrópolis, que por se tratar de uma cidade histórica, confere credibilidade e longevidade a marca e seus valores.

A etapa 2 da visita é marcada por uma diferença na arquitetura, que passa a ser composta por detalhes que remetem o visitante a um ambiente de fábrica. A primeira parada é na sala do mestre cervejeiro, onde vários objetos históricos são apresentados e um laboratório alquimista é reproduzido. Na mesma sala uma grande tela apresenta em vídeo a história da família Kremer e da Bohemia.

A estrutura física da Fábrica guia o visitante em uma jornada histórica e uma experiência sensorial onde artefatos, embalagens, e fotografias compõe um ambiente que auxiliam o visitante a vivenciar as experiências propostas pela marca. As Figuras 5 e 6 mostram parte da sala artefatos, como objetos, fotos e painéis, apresentam o processo de trabalho ao longo do tempo e algumas mudanças da marca. 

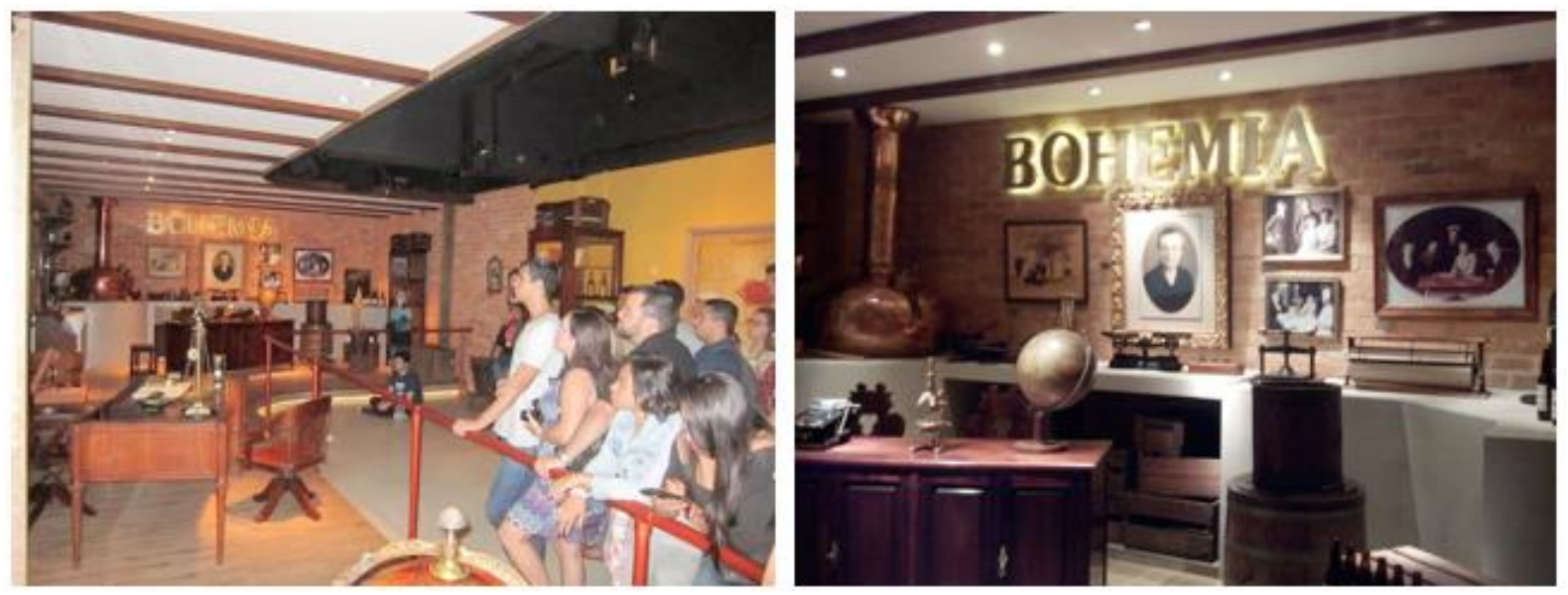

Figura 5 - Sala do mestre cervejeiro com exposição de objetos que contam a história da atividade e da família fundadora e os visitantes assistindo ao filme de apresentação.

Fonte: Próprios autores.
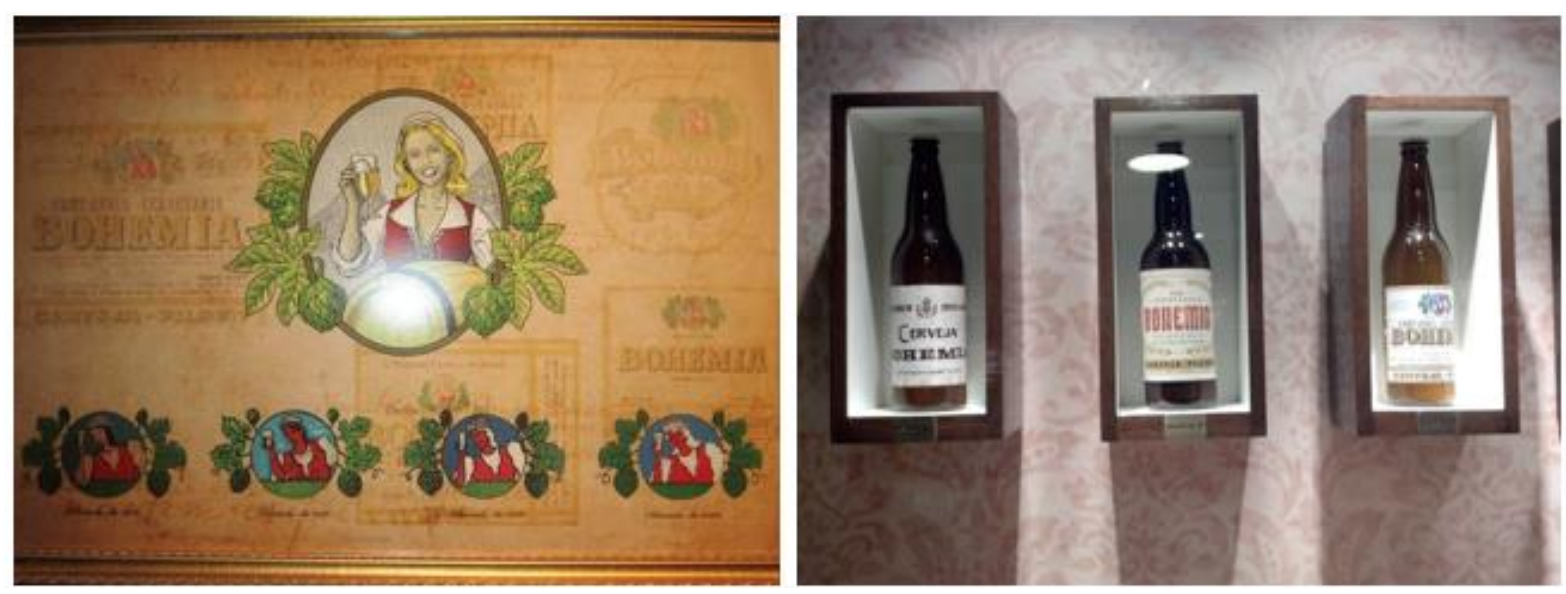

Figura 6 - Objetos que contam a história da cerveja, rótulos e embalagens.

Fonte: Próprios autores.

Nesta etapa, também é possível entrar em salas temáticas que apresentam cada ingrediente da cerveja: sala da água, sala do malte, lúpulo e levedo. Nas salas também são apresentadas informações referentes à qualidade dos ingredientes e a fabricação da Bohemia.

Cabe destacar que, em vários momentos do percurso da visitação, as conexões criadas na apresentação dos objetos se desdobram em conexões e articulações entre a história organizacional e a história pública (Barndt, 2007) produzindo esquemas narrativos de memória coletiva (história da empresa, história da cidade de Petrópolis e história do país) (Foster et al, 2011). Pode-se pensar que é neste momento que a transformação da memória episódica em memória coletiva torna-se mais aparente. Ou seja, torna-se mais visível o processo de construção e compartilhamento dos museus corporativos com a sociedade, de interpretações acerca do passado (Nissley \& Casey, 2002).

Ao mesmo tempo, a estrutura física do espaço de memória em questão guia o visitante em uma jornada histórica permeada por experiências sensoriais na qual artefatos, embalagens e fotografias auxiliam no processo. Assim, após o visitante atravessar a sala do mestre cervejeiro, ocorre um primeiro momento de degustação de cerveja. É um momento mais lúdico e mais teatral. $\mathrm{O}$ guia da visita, de forma performática, diz que como os mestres cervejeiros não foram trabalhar, então os visitantes farão o trabalho deles: ou seja, experimentar a cerveja. É, então, oferecida a cerveja pilsen básica e os guias reforçam a 
informação de que as crianças devem ficar afastadas do carrinho que serve os "novos" mestres cervejeiros.

Esta degustação é feita em uma sala que reproduz os barris de cobre originais usados na produção artesanal da cerveja. O cobre não é mais permitido para esse tipo de produção, no entanto, de forma a manter a tradição e uma aparência nostálgica do local da fábrica onde ainda funciona a produção da cerveja, a empresa utiliza na parte externa de alguns barris a mesma antiga coloração do cobre. Após esta degustação, os visitantes encaminham-se para a última etapa por meio de um corredor onde são expostos os diferentes cartazes de propaganda da marca, de diferentes épocas históricas.

\subsection{A experiência de consumo da marca}

A experiência de consumo está presente em todo o percurso. No entanto, esse talvez seja o momento da visita guiada onde a experiência de consumo aparece de forma mais explícita.

Em um espaço que reproduz uma espécie de bar (com balcão, freezer, copos), a última etapa da visita oferece aos visitantes uma degustação mais técnica e com cervejas especiais. Nesse momento, são ensinados os procedimentos adequados para a identificação dos diferentes aromas e sabores dos produtos da empresa. Cabe ressaltar que em cada visita feita à Fábrica ao longo do trabalho de campo da presente pesquisa foi oferecido um tipo diferente de cerveja. Apenas para ilustrar este ponto, na última visitação (em agosto de 2015) foram oferecidos três lançamentos: a I.P.A. com sabor de jabuticaba; a Witbier com sabor de pimenta rosa; e a Belgian Blonde Ale com erva-mate.

Após essa atividade, todos são encaminhados para a última sala, com jogos e telas interativas. São vários equipamentos sensíveis ao toque, que tiram fotos, fazem montagem e criam rótulos de cerveja com os nomes dos visitantes. Todo material produzido neste espaço (e ao longo do trajeto de visitação) pode ser compartilhado instantaneamente nas redes sociais dos visitantes ou enviados por e-mail, previamente cadastrado na recepção do tour. As garrafas customizadas, no entanto, não são gratuitas e podem ser adquiridas pelo visitante a um valor 12 vezes superior ao da garrafa com o rótulo padrão.

Enfim, no geral, a trajetória da visita está organizada para apresentar: (a) a relevância do produto; (b) o processo de produção com seus ingredientes, técnicas, tradições e rituais de consumo (quem consumia, quando e como); (c) a história da empresa - quando surgiu, o contexto histórico, a qualidade na produção de cerveja e relevância para o país (a primeira do Brasil); e (d) a experiência de consumo por meio da degustação (tipos de cerveja, como beber e quais copos utilizar). Vale destacar que ao final da visita, copos e cervejas são oferecidos para a venda junto com outros objetos da marca.

Deve-se ressalta, ainda, a constante preocupação em vincular a empresa (e seus produtos, por desdobramento) às ideias de tradição, continuidade, permanência e qualidade. Estas aparecem o tempo todo durante o percurso de visita à fábrica, o que corrobora a argumentação dos autores que destacam a importância do uso da história a partir de diferentes imagens e eventos relacionados a uma narrativa, como sua estratégia de comunicação (Foster et al, 2011; Rowlinson et al, 2010; Costa \& Saraiva, 2011). Nesse sentido, a Cervejaria Bohemia, como museu corporativo, cumpre o papel de comunicar os seus valores e a sua história organizacional. Para Foster et al (2011), o uso destes recursos na construção de uma identidade ou de uma marca, é vantajoso porque é socialmente legitimado e com poucas possibilidades de serem copiados pelos concorrentes, visto que contam a história da empresa de forma específica. 


\subsection{As funções do Museu Corporativo}

Após a identificação e descrição da trajetória do tour, buscou-se problematizar esta escolha da empresa a partir das quatro funções primárias dos museus corporativos, definidas por Danilov (1992), quais sejam: (1) preservar a história da companhia; (2) desenvolver um senso de orgulho e identificação do empregado com a empresa; (3) informar visitantes e clientes sobre a empresa, sua linha de produtos ou serviços; (4) influenciar a opinião pública sobre a companhia.

Em relação à função de preservar a história da companhia por meio de constituição de um acervo documental, foram muito poucos os documentos expostos e/ou apresentados para o visitante. Os documentos e artefatos históricos que poderiam amparar e/ou servir de fonte documental para pesquisas acerca da história da cervejaria Bohemia (e por desdobramento da própria região onde ela está localizada) não estão disponíveis no local em toda a sua potencialidade. Nada se sabe ao final da visita ao museu, sobre como ocorria o funcionamento da empresa Bohemia tanto em uma perspectiva histórica quanto em uma perspectiva de gestão, ou seja, em relação ao seu funcionamento, aos seus funcionários, à sua produção, à sua estrutura organizacional, à sua cultura e ao processo de venda da empresa para a AMBEV. Essa situação identificada pode ser um bom indicativo do que a literatura apresenta como sendo um movimento de mudança ou re-significação dos museus corporativos (ver: Nissley \& Casey, 2002; Andreoni, 2011).

Em relação à função de desenvolver um senso de orgulho e identificação do empregado com a empresa, nada foi identificado no tour em questão. No entanto, quando um guia do museu foi indagado pelos pesquisadores se os funcionários da AMBEV fazem esse tour, foi dito que sim: todo novo funcionário da AMBEV faz esse tour, com o objetivo de conhecer melhor a história da Cerveja Bohemia.

Em relação à função de informar visitantes e clientes sobre a empresa, sua linha de produtos ou serviços, em todo o percurso analisado isto ocorre. No entanto, cabe ressaltar que o foco é sempre a marca Bohemia e não a Cervejaria Bohemia ou a atual empresa dona da marca. Ou seja, as informações que o visitante tem acesso falam muito pouco sobre a AMBEV e menos ainda sobre a ligação entre a AMBEV e a história da Bohemia. Por exemplo, não existe a divulgação sobre a importância econômica do grupo ou sobre o processo de aquisição da Bohemia. No último corredor da segunda etapa do trajeto de visitação, por exemplo, apenas de forma indireta e/ou discreta o visitante pode ter uma ideia da capilaridade da distribuição dos produtos ao deparar-se com uma série de caixas com os nomes das cidades aonde se pode consumir a cerveja Bohemia, tais como Caxias do Sul, Boa Vista, Taubaté, entre outras (ver Figura 7 abaixo). 


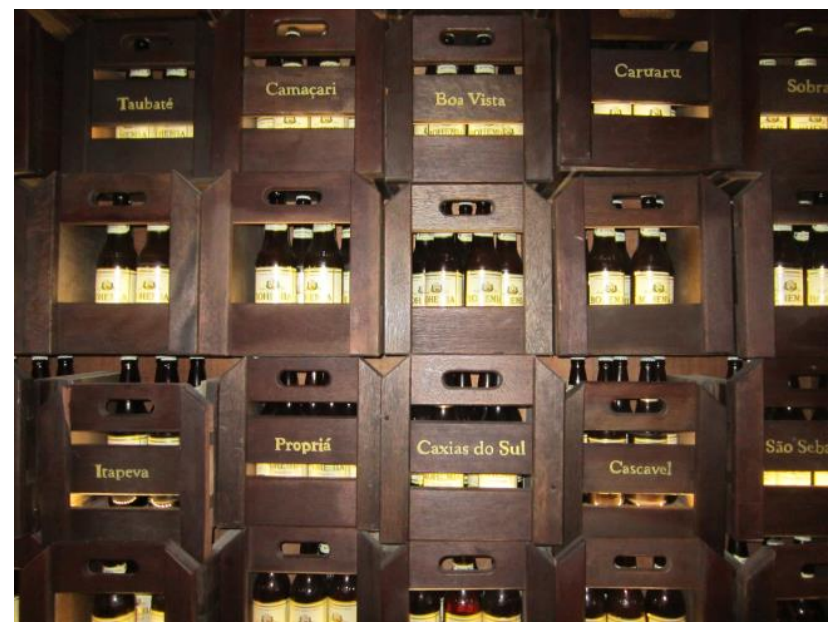

Figura 7 - Objetos que indicam a capilaridade da empresa. Fonte: Próprios autores.

Em relação à última função - de influenciar a opinião pública sobre a empresa - podese considerar que o museu é efetivamente utilizado como forma de impactar positivamente a opinião pública. Assumindo que a cervejaria constrói a sua identidade ancorada em um discurso de incentivo ao consumo de bebidas alcóolicas, pode-se conjecturar que o museu talvez seja, também, o resultado de um esforço de relações públicas para amenizar essa imagem perante a sociedade. Essa intenção pode ser identificada e chamaram a atenção dos pesquisadores, por exemplo, em pelo menos dois momentos durante o percurso da visitação.

O primeiro fato que chamou a atenção é ser permitida a entrada de crianças no museu. Apesar dos vários avisos, as crianças são expostas a ambientes lúdicos e de celebração da cerveja, ou nos termos da visitação, do "ouro líquido". O segundo refere-se à construção de uma narrativa que vincula o hábito de beber cerveja a um hábito transcultural.

Assim, a história da cerveja é contada sempre a partir de uma narrativa que a vincula à própria história da humanidade, naturalizando um produto considerado por muitos como junto com o tabaco - inadequado à saúde. É o que ocorre, por exemplo, quando a cerveja aparece na narrativa e na estética do museu como um rio dourado que atravessa as civilizações no espaço e no tempo, conforme Figura 8 abaixo: 


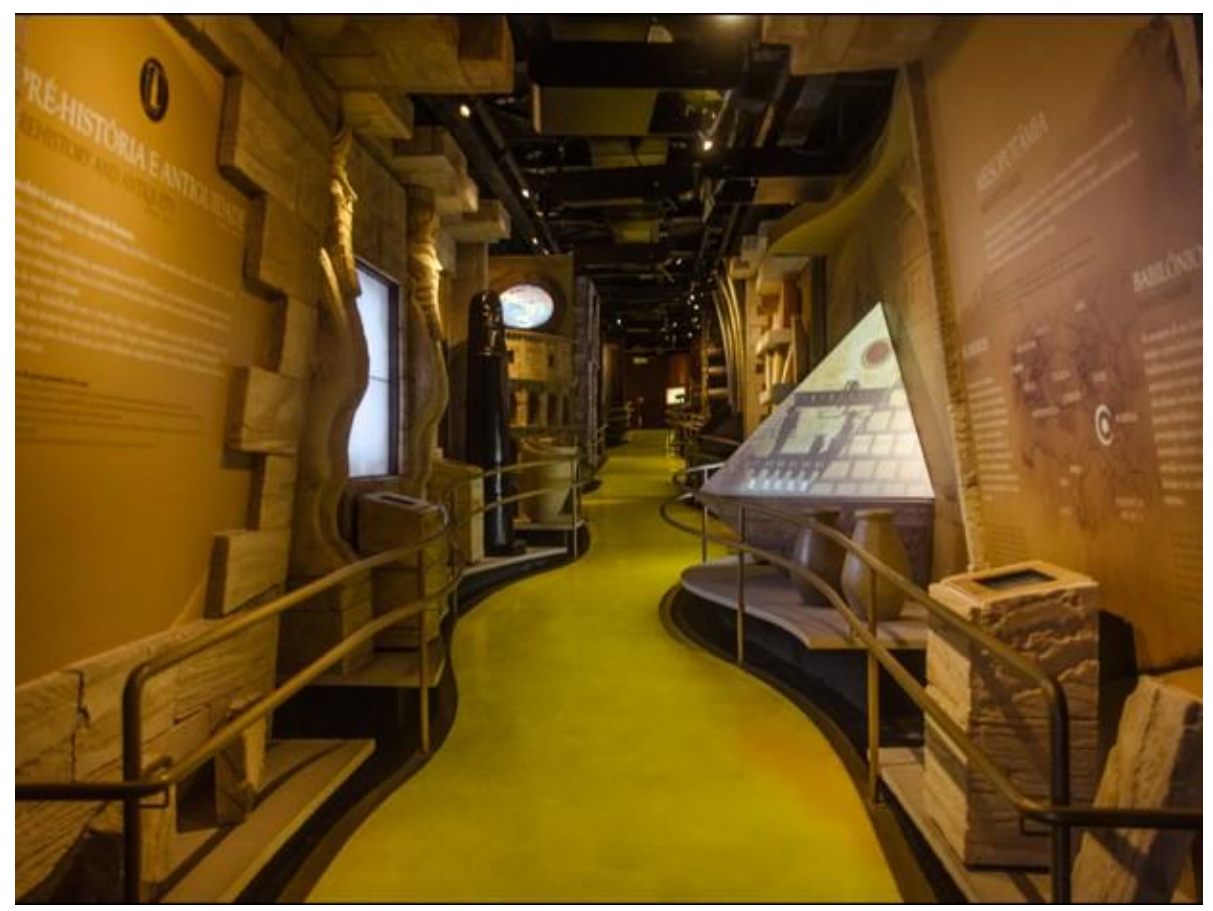

Figura 8 - Percurso da etapa 1 da visita à Fábrica, o rio de cerveja. Fonte: Próprios autores.

Por fim, assumindo que a criação de uma identidade organizacional está diretamente ligada aos objetivos de um museu corporativo (Nissley e Casey, 2002; Danilov, 1992) também buscou-se identificar neste espaço de memória, as quatro narrativas que, de acordo com a literatura, existem em museus corporativos e contribuem para a construção de uma identidade organizacional, quais sejam: narrativas de sucesso (narrativas sobre como a organização está bem estabelecida); narrativas de superação de obstáculos (narrativas sobre quais os obstáculos que a organização teve que superar para ser o que é hoje); narrativas acerca da situação atual (narrativas sobre como a organização apresenta-se hoje); e narrativas de futuro (narrativas sobre o que o futuro reserva para a organização).

Em um primeiro momento, não foi encontrada a presença destas narrativas no museu, o que causou estranheza e levou os pesquisadores a refletir sobre essa situação. A história da Cervejaria Bohemia talvez não seja o foco do museu porque não é essa construção de identidade que talvez a AMBEV, a atual proprietária da marca, almeje. Pelo contrário, como construir e expor uma identidade organizacional de uma empresa que não existe mais? Uma empresa que foi comprada, desconstruída organizacionalmente, passando a ser apenas mais uma marca em um grande portfólio de produtos? Neste sentido, esse silêncio pode ser atribuído ao deslocamento da ênfase no espaço de memória como um depósito histórico da empresa para a experiência com um ativo estratégico bastante específico: a marca de cerveja Bohemia.

Portanto, o Museu Bohemia pode ser observado, também, sob a perspectiva de uma experiência de marketing. Nesse sentido, vale observar que algumas "atrações" da visita com destaque para a possibilidade de "provar" grãos e farelo de cevada ou trigo, de tirar fotografias digitais em cenários da cervejaria ou de jogar videogames cujas narrativas passam pela fabricação de cerveja - são especialmente identificados com outras experiências de marca realizadas no Brasil. Com efeito, Martyniuk (2010) analisa o projeto denominado $P \& G 5 D$ Experience, que funcionou no segundo semestre de 2010, no shopping Market Place em São Paulo. 
Nesta experiência de marca, a marca mãe $(\mathrm{P} \& \mathrm{G})$ divulgou marcas de seus produtos, como Pringles, Duracell e Head and Shoulders, por meio da criação de uma loja conceito, que permitiu aos consumidores experimentar sensações ligadas aos universos de sentido de cada produto. O trabalho de Martyniuk (2010) documenta atividades muito semelhantes às encontradas no Museu Bohemia, conforme as Figuras 9 e 10.
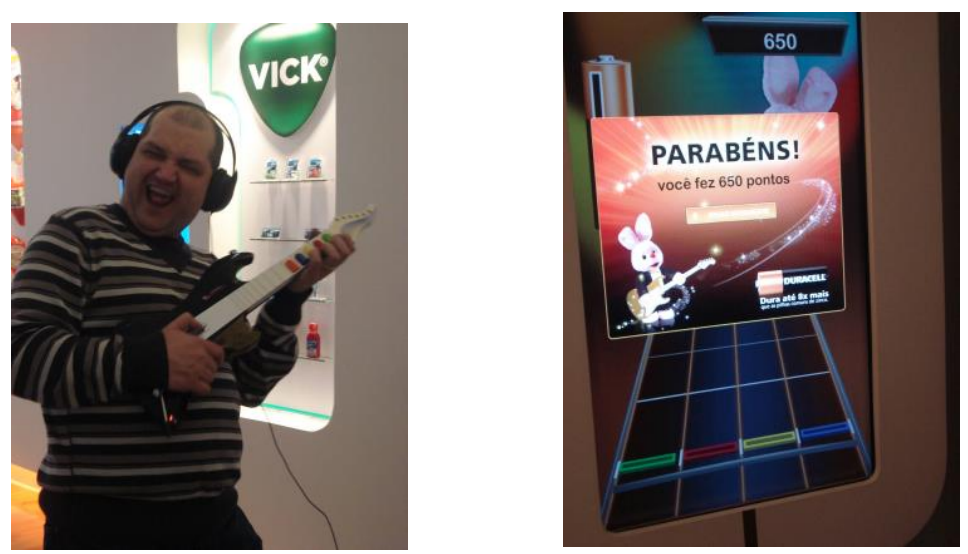

Figura 9 - P\&G 5D Experience. Visitante utilizando o brinquedo Guitar Hero no box das pilhas Duracell. Fonte: Martyniuk (2010)
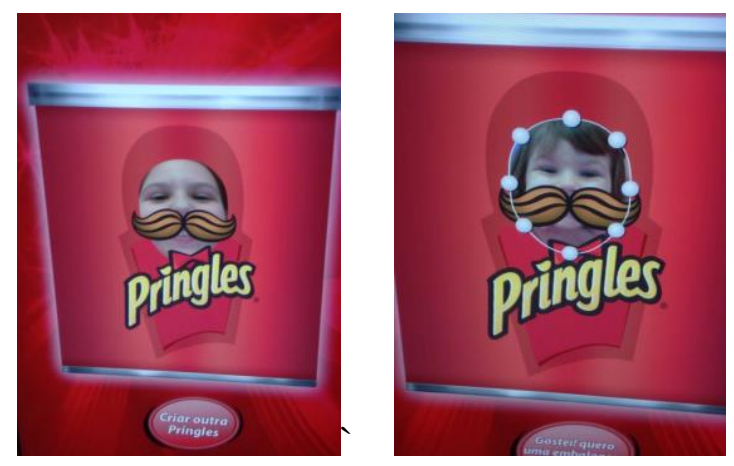

Figura 10 - P\&G 5D Experience. Fotos produzidas no espaço Pringles Fonte: Martyniuk (2010)

\section{Considerações finais}

A presente pesquisa teve por objetivo identificar, descrever e problematizar o tour pela fábrica da Cervejaria Bohemia como um espaço estratégico de memória corporativa. Para alcançar este objetivo, todas as salas que compõem o percurso foram identificadas, descritas e depois analisadas à luz das quatro funções primárias dos museus corporativos propostas por Danilov (1992) e Nissley e Casey (2002). Como já foi dito, das quatro funções, duas não foram identificadas (preservar a história da empresa; e desenvolver um senso de orgulho e identificação do empregado com a empresa). As outras duas foram identificadas. Em todo o percurso o visitante é informado sobre a empresa e sua linha de produtos ou serviços. No entanto, cabe ressaltar que o foco maior é sempre a marca Bohemia e não a Cervejaria Bohemia ou a atual empresa dona da marca, a AMBEV. Em relação à função de influenciar a opinião pública sobre a empresa, pode-se considerar que o museu é efetivamente utilizado como forma de impactar positivamente a opinião pública. 
Por um lado, pode-se afirmar que a Cervejaria Bohemia é um museu corporativo que utiliza os recursos das memórias cultural, episódica e coletiva para construção de uma narrativa histórica. No entanto, no que diz respeito à construção de uma identidade organizacional, este museu corporativo ainda não explorou todo o seu potencial estratégico, parecendo tender para uma configuração focada apenas na marca e na experiência da marca de seus produtos. Ou seja, o foco recai menos na história da Cervejaria Bohemia (empresa) do que na história da Cerveja Bohemia (marca do produto).

Assim, pode-se argumentar que a empresa privilegia uma função utilitária bem específica para o uso da memória e de fatos históricos: legitimar a sua marca empresarial, reforçando o discurso da história e da tradição. Estes apresentam-se, inclusive, como os pilares de suas campanhas de comunicação, extrapolando os muros do seu espaço de memória. Por exemplo, a atual campanha publicitária reforça as ideias de história e tradição no mercado por meio de slogans como: "A primeira cerveja do Brasil"; "A primeira e melhor cerveja do Brasil"; "Desde 1853"; "Há 150 anos o mesmo prazer"; e "O mesmo prazer desde 1853" (Bohemia, 2014).

Enfim, ao assim proceder, a gestão das memórias torna-se, então, um instrumento de comunicação: a uma determinada imagem de marca pretendida, são selecionados valores, identidade, cultura, símbolos e ritos que formam uma memória capaz de suportar tal imagem. Como desdobramento, a estrutura física e o arranjo temático da Cervejaria Bohemia guiam o visitante em uma jornada histórica e em uma experiência sensorial com a marca que, mais do que estabelecer um lugar de memória, proporciona - principalmente -mais uma experiência de consumo. Dessa forma, a presente pesquisa abre uma interessante possibilidade de discussão: como analisar o museu Bohemia pela dupla perspectiva de museu corporativo e experiência de marca? É possível conciliar a natureza distinta dessas duas proposições institucionais? Até que ponto os dois conceitos convergem? A partir de que momento os dois conceitos passam a concorrer ou, mais problemático, a inviabilizar-se mutuamente? Tais questões estão fora do escopo da presente pesquisa, mas colocam-se como avenidas para futuros estudos.

\section{Referências}

Andreoni, R. (2011) Museu, Memória e Poder. Revista Em Questão, Porto Alegre, 17(2), 167-179, jul/dez.

Anteby, M. Molnar, V. (2012) Collective Memory meets Organizational identity: Remembering to Forget in a Firm's Rhetorical History. Academy of Management Journal, 55(3), 515-540.

Barndt, K. (2007) Fordist Nostalgia: History and Experience at Henry Ford. Rethink History, 11(3), $379-410$.

Bohemia. (2014) Página principal. Disponível em: http://www.bohemia.com.br, recuperado em 30 de abril de 2014.

Bohemia. (2015a) Página principal. Disponível em: http://www.bohemia.com.br, recuperado em 02 de maio de 2015a.

Bohemia. (2015b) Página principal. Disponível em: http://www.bohemia.com.br, recuperado em 02 de maio de 2015b.

Booth, C.; Rowlinson, M. (2006) Management and organizational history: prospects. Management \& Organizational History, London, 1(1), p. 5-30.

Castellani, P.; Rossato, C. (2014) On the communication value of the company museum and archives. Journal of Communication Management, 18(3), p.240-253. 
Costa, A.M.; Saraiva, L.A.S. (2011). Memória e formalização social do passado nas organizações. Revista de Administração Pública, 45(6), 1761-80.

Danilov, V. (1992). A Planning Guide for Corporate Museums, Galleries, and Visitor Centers. Greenwood Press, Westport.

Feldman, R.M.; Feldman, S.P. (2006). What Links the Chain: An Essay on Organizational Remembering as Practice. Organization, 13(6): 861-887.

Figueiredo, M. (2009) Da Memória dos Trabalhadores à Memória Petrobras: história de um projeto. Dissertação de Mestrado. CPDOC - FGV, Rio de Janeiro, Brasil.

Foster, W. M., Suddaby, R., Minkus, A; Wiebe, E. (2011). 'History as Social Memory Assets: The example of Tim Hortons'. Management \& Organizational History, 16(1), 101-120.

Halbwachs, M. (1992) On Collective Memory. Chicago: The University of Chicago Press.

O GLOBO. (2014) Caderno Boa Viagem. Disponível em: http://oglobo.globo.com/estilo/boaviagem/petropolis-cidade-imperial-capital-da-cerveja-4940563, recuperado em dez. de 2014.

O GLOBO. (2014b) Caderno Região Serrana. Disponível em: http://g1.globo.com/rj/regiaoserrana/noticia/2013/09/museu-da-cerveja-encanta-turistas-e-moradores-em-petropolis-

rj.html., recuperado em dezembro de 2014b.

Kotler, P. ; Keller, K.L. (2012) Administração de Marketing, 14ª ed. São Paulo: Pearson Education do Brasil.

Lipovetsky, Gilles. (2004). Os tempos hipermodernos. São Paulo: Editora Barcarolla.

Martyniuk, V. L. (2010) Regimes de sentido e de interação na ocupação de espaços pelas ações de advertainment. Caderno de Discussão Centro de Pesquisas Sociossemióticas 1(1). Nassar, P. (2007). Relações Públicas na construção da responsabilidade histórica e no resgate da memória institucional das organizações. São Caetano do Sul: Difusão Editora.

Nissley; N. and Casey, A. (2002). 'The Politics of the Exhibition: Viewing Corporate Museums Through the Paradigmatic Lens of Organizational Memory'. British Journal of Management, 13 (52), 535-543.

Nora, P. (1993). Between Memory and History: Les lieux de mémoire. Representations, 26, California: University of California Press.

Ravasi, D. (2014) Identidade Organizacional e Memória. Organicom, 11(20), 40 - 48.

Rhees, D. J. (1993). Corporate Advertising, Publica Relations and Popular Exhibits: The Case of Du Pont. History and Tecnology, 10, 67-75.

Ribeiro, A. P. G.; Barbosa, M. (2007) Memória, relatos autobiográficos e identidade institucional. Comunicação e Sociedade, 47: 99-114.

Rowlinson, M., Booth, C., Clark, P., Delahaye, A. and Procter, S. (2010) 'Social Remembering and Organizational Memory. Organization Studies, 31(1), 69-87.

Schultz, M.; Hernes, T. A. (2013). Temporal Perspective on Organizational Identity. Organization Science, 24(1), january-february, 1-21.

Stigliani, I.; Ravasi, D. (2007) Organizational artefacts and the expression of identity in corporate museums as Alfa Romeo, Kartell, and Piaggio. In: Lerpold, L.; Ravasi, D.; Van Rekom, J. Soenen G. (Ed) Organizational identity in practice. New York: Routledge. Walsh J. P.; Ungson, G. R. (1991). The Academy of Management Review. 16(1), 57-91. 